\title{
In memoriam de Teresa Amado
}

José Mattoso

\section{(2) OpenEdition \\ Journals}

\section{Edição electrónica}

URL: http://journals.openedition.org/medievalista/262

DOI: 10.4000/medievalista.262

ISSN: 1646-740X

\section{Editora}

Instituto de Estudos Medievais - FCSH-UNL

\section{Refêrencia eletrónica}

José Mattoso, «In memoriam de Teresa Amado », Medievalista [Online], 15 | 2014, posto online no dia

01 janeiro 2014, consultado no dia 01 maio 2019. URL : http://journals.openedition.org/

medievalista/262 ; DOI : 10.4000/medievalista.262

(C) IEM 
Título: In memoriam de Teresa Amado

Autor: José Mattoso

Universidade: Universidade Nova de Lisboa

Faculdade e Departamento / Unidade de Investigação: Instituto de Estudos Medievais FCSH / UNL

Código Postal: 1069-061 LISBOA

Cidade: Lisboa

País: Portugal

Contacto: jjmtts@outlook.com

Fonte: Medievalista [Em linha]. №15, (Janeiro - Junho 2014). Dir. José Mattoso. Lisboa: IEM.

Disponível em: http://www2.fcsh.unl.pt/iem/medievalista/

ISSN: 1646-740X

Data do texto: 22 de Outubro de 2013

\section{In memoriam de Teresa Amado}

José Mattoso

Maria Teresa Amado, inesperadamente falecida no dia 5 de Agosto, representava o pouco que ainda restava, na Universidade portuguesa actual, do que ela tinha de bom antes do 25 de Abril. O que ela tinha de retrógrado, de ostentação sem fundamento, de saber formal e inútil, de submissão a uma ideologia alienante, tudo isso desapareceu há muito. Com efeito, a Academia da época salazarista não tinha só lacaios do regime. Para 
sermos justos, temos de recordar nomes como os de L. F. Lindley Cintra, Manuel Antunes, Orlando Ribeiro, J. Prado Coelho, Maria de Lurdes Belchior, Vitorino Nemésio, todos da Faculdade de Letras de Lisboa, ou ainda como Adérito Sedas Nunes e Francisco Pereira de Moura, da Faculdade de Economia de Lisboa, J. S. Silva Dias, da Faculdade de Letras de Coimbra, Joaquim Romero de Magalhães, da Faculdade de Economia de Coimbra. E outros... Nos anos 50 e 60, sustentaram com brio a dignidade do ensino universitário. Resistiram firmemente à distorsão imposta pelo regime à cultura portuguesa.

A renovação da Universidade trazida pelo 25 de Abril não se deveu só aos jovens marxistas que nela entraram em massa (e depressa se dispersaram). Deveu-se sobretudo à geração formada por docentes como os que citámos. Os seus discípulos souberam preservar a herança intelectual transmitida pela Academia antes do 25 de Abril e conjugá-la com a renovação internacional das Ciências Sociais e Humanas, que então se processava com vigor nas universidades europeias. Daí resultou, em Portugal, entre 74 e 85, um ensino universitário hesitante, eclético, pouco sistemático, disperso, de nível científico duvidoso e teoricamente inseguro, apesar da boa vontade dos seus responsáveis. Reivindicava a liberdade intelectual, rejeitava ortodoxias, respeitava teorias e opiniões, praticava o diálogo entre as várias ciências humanas e recomendava o convívio com as artes performativas. O seu pendor eclético não colidia com um pendor tendencialmente humanista.

Teresa Amado representa bem o que de melhor praticou a geração a que me refiro. A formação inicial, que deveu a Lindey Cintra e Vitorino Nemésio, consolidou-se e diversificou-se depois de 74, graças aos contactos directos com a docência e a investigação anglo-saxónica, como leitora do King's College em Cambrigde. Durante alguns anos, de 1978 a 1985, publica na Colóquio/Letras recensões breves de obras de Barthes e de Kristeva, e de autores portugueses recentes. Mas a partir de 1985 consagra-se quase exclusivamente ao estudo da concepção da História em Fernão Lopes. Como resultado das suas investigações, viria depois a apresentar em provas públicas a tese de doutoramento a que deu o expressivo título de Fernão Lopes, contador de História (1991). O caráter sistemático da investigação que então fez transparece na extensa e completa Bibliografia de Fernão Lopes que publicou no mesmo ano. Depois, não deixaria mais de analisar o texto do cronista, para compreender 
e explicar as suas concepções acerca da memória e de tempo. Mas estudou também outros temas especialmente significativos como as festas, o riso, ou a guerra (ver a obra colectiva A Guerra até 1450, 1995, e O passado e o presente. Ler Fernão Lopes, 2007), aprofundando cada vez mais o seu conhecimento do texto do genial cronista. Além disso, colaborou em obras colectivas, colóquios e investigações sobre várias outras matérias da literatura portuguesa anterior ao século XVI, sobretudo a literatura medieval, e publicou novas edições de obras bem conhecidas, como a Menina e moça de Bernardim Ribeiro e o Amadis. A forma como acompanhava jovens investigadores, como os motivava e lhes transmitia o seu próprio entusiasmo faziam de Teresa Amado uma docente muito querida dos seus alunos e de todos os que com ela trabalhavam. Em várias ocasiões prestou uma inestimável colaboração ao Instituto de Estudos Medievais e à revista Medievalista OnLine.

Em 2005 tornou-se membro da "Medieval Chronicle Society", onde teve oportunidade de trocar impressões com os melhores especialistas internacionais deste género literário, e de verificar o quase completo desconhecimento fora de Portugal da obra de Fernão Lopes e da sua originalidade, no contexto da historiografia europeia. Em 2009 deu a conhecer a importância das suas crónicas na revista da Associção ("Time and Memory in three Portuguese Chronicles”, The Medieval Chronicle, VI, Rodopi, pp. 91-103). Foi então criado pela mesma Associação o grupo de tradução das crónicas de Fernão Lopes para inglês, do qual foi nomeada coordenadora. Entretanto tinha sido também criado um grupo dedicado à fixação do texto crítico e à publicação das mesmas crónicas do qual foi também coordenadora e que em Portugal seria por si desenvolvido no Centro de Estudos Comparatistas da Faculdade de Letras de Lisboa. A primeira destas tarefas, que abraçou de alma e coração, absorveu-a completamente. O exercício da tradução para outra língua obrigou-a uma nova percepção e descoberta do sentido do texto original que a análise literária nem sempre conseguia transmitir. A plena comunhão com o texto do seu autor preferido tornou-se uma verdadeira paixão. Tendo o trabalho já muito adiantado, sobreveio-lhe um cancro de evolução rápida e dificilmente operável. A única hipótese de continuar a tradução dependia do êxito, ainda que remoto, de uma operação cirúrgica de alto risco em Paris. O desejo de terminar a sua obra decidiu a sua escolha. Vencida a prova, recobrou forças para continuar, com o entusiasmo e a determinação de sempre. Na semana anterior ao seu falecimento mandava-me um mail cheio de 
optimismo e de esperança, como quem estava prestes a alcançar a meta. De facto alcançou-a seis dias depois. A da vida, a definitiva, a única meta verdadeira.

A paixão com que se entregou à compreensão e à tradução de Fernão Lopes exprime uma característica maior da sua personalidade única. A quem a conheceu, mesmo superficialmente, ocorrem qualificativos como modéstia, simplicidade, sensibilidade, naturalidade, humanidade, tranquilidade, doçura... Virtudes pouco comuns numa professora universitária. Associava-as sem esforço a normas de exigência e rigor indispensáveis a qualquer investigação credível. Mas a sua têmpera de investigadora não se contentava com esta invulgar aliança. A racionalidade da crítica unia-se também ao pendor artístico recebido por via familiar, que inspirava a originalidade e a criatividade de tudo o que fazia. A sua especialização numa matéria bem definida não a impedia de se interessar por outros aspectos e figuras dos estudos literários (Camões, Shakespeare, Diderot, Bernardim Ribeiro, Sophia de Mello Breyner, Maria Velho da Costa, Almada Negreiros...) nem de conviver com outras Artes, como o teatro e a pintura (seu pai, Fernando Amado, actor e encenador, foi um dos fundadores da Casa da Comédia e durante muitos anos professor do Conservatório; seu irmão Manuel é arquitecto e pintor, e também praticou o teatro). Compreende-se assim que tivesse dado ao último artigo que escreveu para a revista Colóquio / Letras o título "Traduzir com música e paixão" (2011, n 176, pp. 84-94). Procurava, creio eu, um exemplo a seguir. Encontrava-o na tradução do Hamlet por Sophia de Mello Breyner. Traduzir, para ela, não era um problema de técnica mas de inspiração. Um caminho iluminado pela arte e inflamado pela paixão.

A interpretação racional e análise crítica do texto não a impediam, pois, de ir buscar o melhor da sua obra a uma vivência plena da emoção estética. Teresa Amado não se preocupou muito em saber de que lado do Universo vinha a sua sensibilidade ao inominável, e a fidelidade a uma incumbência que a ultrapassava. Infelizmente já não está connosco para nos ajudar a descobri-lo. Mas, se estivesse, continuaria a dizer-nos que o mistério não se descobre só com a razão. 


\section{COMO CITAR ESTE ARTIGO}

\section{Referência electrónica:}

MATTOSO, José - "In memoriam de Teresa Amado". Medievalista [Em linha]. Nº15, (Janeiro - Junho 2014). [Consultado dd.mm.aaaa]. Disponível em http://www2.fcsh.unl.pt/iem/medievalista/MEDIEVALISTA15/mattoso1502.html.

ISSN 1646-740X.

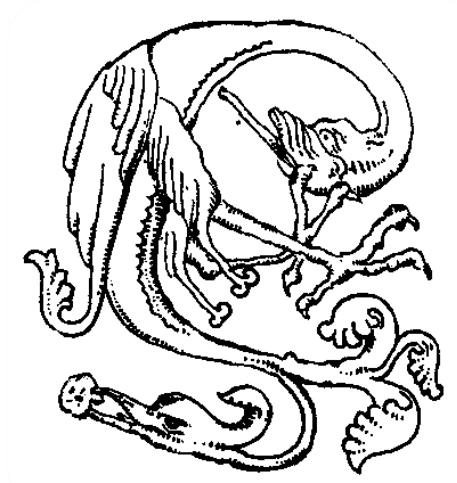

